\title{
BMJ Open Retrospective economic analysis of the transfer of services from hospitals to the community: an application to an enhanced eye care service
}

\author{
Thomas Mason, ${ }^{1}$ Cheryl Jones, ${ }^{1}$ Matt Sutton, ${ }^{1}$ Evgenia Konstantakopoulou, ${ }^{2,3,4}$ \\ David F Edgar, ${ }^{2}$ Robert A Harper, ${ }^{5}$ Stephen Birch, ${ }^{1,6}$ John G Lawrenson ${ }^{2}$
}

To cite: Mason T, Jones C, Sutton M, et al. Retrospective economic analysis of the transfer of services from hospitals to the community: an application to an enhanced eye care service. BMJ Open 2017;7:e014089. doi:10.1136/ bmjopen-2016-014089

- Prepublication history and additional material are available. To view these files please visit the journal online (http://dx.doi.org/ 10.1136/ bmjopen-2016-014089)

Received 30 August 2016 Revised 17 January 2017 Accepted 3 March 2017

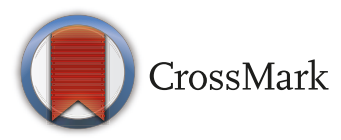

For numbered affiliations see end of article.

Correspondence to Thomas Mason; thomas. mason@manchester.ac.uk

\section{ABSTRACT}

Objective This research aims to evaluate the wider health system effects of the introduction of an intermediate-tier service for eye care.

Setting This research employs the Minor Eye Conditions Scheme (MECS), an intermediate-tier eye care service introduced in two London boroughs, Lewisham and Lambeth, in April 2013.

Design Retrospective difference-in-differences analysis comparing changes over time in service use and costs between April 2011 and October 2014 in two commissioning areas that introduced an intermediate-tier service programme with changes in a neighbouring area that did not introduce the programme.

Data sources MECS audit data; unit costs for MECS visits; volumes of first and follow-up outpatient attendances to hospital ophthalmology; the national schedule of reference costs.

Main outcome measures Volumes and costs of patients treated.

Results In one intervention area (Lewisham), general practitioner (GP) referrals to hospital ophthalmology decreased differentially by $75.2 \%(95 \% \mathrm{Cl}-0.918 \%$ to $-0.587 \%$ ) for first attendances, and by $40.3 \%$ for follow-ups $(95 \% \mathrm{Cl}-0.489 \%$ to $-0.316 \%)$. GP referrals to hospital ophthalmology decreased differentially by $30.2 \%$ $(95 \% \mathrm{Cl}-0.468 \%$ to $-0.137 \%)$ for first attendances in the other intervention area (Lambeth). Costs increased by $3.1 \%$ in the comparison area between 2011/2012 and $2013 / 2014$. Over the same period, costs increased by less $(2.5 \%)$ in one intervention area and fell by $13.8 \%$ in the other intervention area

Conclusions Intermediate-tier services based in the community could potentially reduce volumes of patients referred to hospitals by GPs and provide replacement services at lower unit costs.

\section{INTRODUCTION}

GPs in the English National Health Service (NHS) perform a gate-keeping function; rationing patient access to secondary care. This function is intended to prevent unnecessary use of secondary care, but it can risk delay in patients receiving specialised treatment. ${ }^{1}$ Such delays can cause patients to make

\section{Strengths and limitations of this study}

- We exploit data on costs and activity to show the relationship between the introduction of intermediate-tier services and supply and demand/ need.

- We use a difference-in-differences approach to identify the effects of the scheme over time compared with an area with similar characteristics.

- We provide a breakdown of referral patterns.

- While we compare areas that have similar characteristics, we could not rule out all potential sources of confounding.

- The findings of this study are not necessarily generalisable across the UK.

multiple trips to visit a GP, generating higher costs to the patient and imposing additional demands on primary care that, if avoided, would free up primary care capacity to serve other patient needs more appropriately.

Patients may not obtain secondary care quickly due to waiting lists for hospital-based care. While this may not induce a large burden on patients who have non-urgent conditions, there is evidence to suggest that patients will experience disutility from waiting. ${ }^{2}$ Waiting times across England's NHS hospitals have declined, ${ }^{3}$ but new strategies are being implemented to maintain this performance.

A recent initiative has been to introduce intermediate-tier services (ITS) for selected services, such as ophthalmology, dermatology ${ }^{4}$ and diabetes. ${ }^{5}$ ITS are intended to reduce demand on secondary care by creating a substitute for hospital-based care to which GPs may refer patients or patients may access directly. Sibbald et at described four forms of ITS: (1) transfer of services from hospitals to primary care; (2) relocation of hospital services to primary care; (3) joint working between primary and secondary care; and 
(4) interventions that change the referral behaviour of primary care practitioners.

Very few previous studies have sought to assess the wider healthcare system effects of introducing ITS, and these studies suggest that further research is needed to assess the costs and benefits of ITS. Sibbald et $a l^{6}$ suggest that both transferring secondary care services into primary care and changing referral patterns are effective in reducing hospital outpatient activity, but note that the quality of care may decline and costs may increase. Sibbald $e t a l^{7}$ conducted an evaluation of the economic impact of shifting care within six specialities from hospitals to non-hospital settings. They found that ITS reduced the time patients waited for treatment, improved the technical quality of care and increased overall satisfaction with access to care when compared with hospital-based services. Coast $e t a l^{4}$ carried out cost effectiveness and cost consequences analyses of ITS in dermatology finding that, although waiting times reduced and patient satisfaction increased, costs were also higher for patients treated by ITS compared with those referred to hospital.

In this paper, we examine how the introduction of an ITS for eye care services in two commissioning areas in England affected the numbers of patients treated by hospital ophthalmology by comparing changes in the number of patients treated at hospital between the areas with ITS and a neighbouring area in which no ITS was introduced. We also examine the cost consequences of introducing an ITS by considering total costs at hospitals and of the ITS.

\section{The minor eye conditions scheme}

Changes to the regulations governing optometry in 2000 allowed community optometrists to 'decide not to refer patients with a disease or abnormality of the eye to a medical practitioner'. ${ }^{8}$ Further amendments in 2005 allowed optometrists to refer patients to more specialised optometry services. ${ }^{9}$ This change has led to the development of enhanced eye service schemes (community optometric services) across the UK, which allow for the treatment and management of acute eye care conditions by accredited optometrists in non-hospital settings. ${ }^{10}$ General Ophthalmic Service (GOS) provision is not identical across the UK. Notably in Scotland, where a new GOS contract has been in operation since April 2006. Among the differences that apply in Scotland compared with the rest of the UK, a supplementary eye examination on a glaucoma suspect could be performed in Scotland under the GOS contract; however, this would fall outside the GOS in the rest of the UK.

The Minor Eye Conditions Scheme (MECS) is an NHS-funded ITS providing patients with access to specialised eye care within the community. Under this scheme, patients presenting to their GP with an eye problem, and satisfying specific inclusion criteria, are referred to accredited community optometrists.
Patients can be referred to the ITS for a range of eye conditions including (but not limited to) red eye, sticky eye, watery eye, irritation or inflammation of the eyes and recently occurring flashes and floaters. The scheme also allows patients direct access to an accredited MECS optometrist without a GP referral.

\section{DATA}

We obtained administrative data for the ITS for the period 2 September 2013 to 30 August 2014. These data describe the volume of patients being referred to the MECS, the presenting eye condition, the number of patients referred onward for hospital-based ophthalmology care and the main types of treatments given.

We also obtained counts of first and follow-up outpatient attendances to hospital ophthalmology clinics in the two areas that introduced the MECS. The data were provided for the period 1 April 2011 to 31 October 2014. Equivalent data were also obtained for a neighbouring commissioning area in which an ITS was not introduced. We distinguish between referrals from three possible sources: GPs, consultant-to-consultant and 'other', which included accident and emergency, national screening programmes and self-referrals.

We acquired the National Schedule of Reference Costs for 2012/2013 which contains the average cost per outpatient attendance to ophthalmology clinics in hospitals for the middle year of the analysis period. The unit costs for the MECS were obtained from the commissioning organisations. The costs of each type of visit were first hospital outpatient attendance £144.04, follow-up hospital outpatient attendance $£ 83.92$, first MECS attendance $£ 47.00$ and follow-up MECS attendance £28.00.

\section{METHODS}

We compare numbers of first and follow-up attendances at hospitals and the ITS in the two commissioning areas over time. We use difference-in-differences to estimate the impact of the introduction of the ITS on outpatient attendances at hospital ophthalmology clinics. The intervention areas are two commissioning areas (Lambeth and Lewisham) in close geographical proximity in Greater London who jointly introduced the ITS in April 2013. The comparison area (Southwark) is a neighbouring commissioning area that did not introduce an ITS.

We compare baseline data covering the period September 2011 to April 2013 to data from April 2013 to October 2014, after the introduction of the ITS. We analysed the natural logarithm of the volume of outpatient attendances at each hospital from each commissioning area, which allows for simple presentation of relative changes. There were three commissioning areas with populations served by three hospitals, giving nine hospital-commissioning area combinations. We observe patient volumes for each of these combinations for 13 quarters. 
We estimate the difference-in-differences model using ordinary least squares regression. Difference-in-differences measures the change over time in the intervention areas minus the change over time in the comparison area. We use linear regression and include binary indicators for each quarter and for each hospital-commissioner combination to control for baseline differences in activity rates. The difference-in-differences effect is given by the coefficient on an interaction between an indicator for an intervention area and an indicator for the quarter in the postintervention period.

The key assumption underpinning the difference-in-differences estimator is that the changes over time are expected to be the same in the intervention areas as in the comparison area in the absence of the intervention. ${ }^{11}$ We examined area-level characteristics for Lambeth, Lewisham and Southwark: three boroughs located in South East London. Southwark lies between Lambeth and Lewisham with Lambeth to the west and Lewisham to the east. These areas are similar across many characteristics including population density, mean and median age, gender, level of deprivation, education, employment, ethnicity and religion. Table 1 presents key characteristics for the three local authority areas.

\section{RESULTS}

We show volumes of hospital outpatient ophthalmology attendances for first and follow-up visits from all referral sources in table 2 for the three areas. In Lambeth, total hospital attendances increased by $3.3 \%$ between February 2012 and 2014. Hospital attendances in Lewisham decreased by $5.3 \%$ over the same period. In the comparison area (Southwark), hospital attendances increased by 7.4\% between February 2012 and 2014.

The difference-in-differences analysis reveals diverging patterns for the two ITS areas (table 3). For Lambeth, first attendances of ophthalmology at Hospital B referred by GPs were differentially reduced by $30.2 \% \quad(95 \%$ CI $-0.468 \%$ to $-0.137 \%$ ) compared with Southwark.

Table 1 Characteristics of the two intervention areas and the comparison area

\begin{tabular}{|c|c|c|c|}
\hline Characteristics & Lambeth (Intervention) & Lewisham(Intervention) & Southwark(Comparison) \\
\hline Resident population & 303086 & 275885 & 288283 \\
\hline \multicolumn{4}{|l|}{ Age and gender } \\
\hline Mean age & 33.7 & 34.6 & 33.7 \\
\hline Median age & 31.0 & 33.0 & 32.0 \\
\hline Female, \% & 50.21 & 51.08 & 50.53 \\
\hline \multicolumn{4}{|l|}{ Deprivation } \\
\hline Not deprived, \% & 39.90 & 38.40 & 36.20 \\
\hline Deprived $1-2$ dimensions, $\%$ & 52.50 & 53.90 & 55.70 \\
\hline Deprived 3-4 dimensions, \% & 7.60 & 7.70 & 8.50 \\
\hline Education: 5+ O-levels/GCSEs, \% & 40.70 & 35.50 & 37.40 \\
\hline Economically active, \% & 46.50 & 40.10 & 42.20 \\
\hline \multicolumn{4}{|l|}{ Ethnicity } \\
\hline White, \% & 57.10 & 53.50 & 54.20 \\
\hline Mixed, \% & 7.60 & 7.40 & 6.20 \\
\hline Asian, \% & 6.90 & 9.30 & 9.43 \\
\hline Black, \% & 26.00 & 27.20 & 26.90 \\
\hline Arab, \% & 0 & 0.50 & 0.90 \\
\hline Other, \% & 0 & 2.10 & 2.40 \\
\hline \multicolumn{4}{|l|}{ Religion } \\
\hline Christian, \% & 52.50 & 52.80 & 53.10 \\
\hline Muslim, \% & 8.50 & 6.44 & 7.10 \\
\hline Other, \% & 3.70 & 4.70 & 3.10 \\
\hline No religion, \% & 26.70 & 27.24 & 28.00 \\
\hline
\end{tabular}

Education (no person in the household has at least level 2 education (GCSE Equiv) and no person aged 16-18 is a full-time student); Health and disability (any person in household with 'bad' or 'very bad' health or long-term health problem); Housing (household is overcrowded, is in a shared dwelling or has no central heating).

Source: Office for National Statistics, Neighbourhood Statistics, 2011 census (https://www.neighbourhood.statistics.gov.uk/ dissemination/);\%20Deprivation dimensions: employment (any member of household that is not a full-time student that is unemployed or long-term sick).

GCSE, General Certificate of Secondary Eduction. 
Table 2 Volumes of hospital outpatient ophthalmology attendances from September 2011 to August 2014

\begin{tabular}{lllllll}
\hline & $\begin{array}{l}\text { September 2011 } \\
\text { to February 2012 }\end{array}$ & $\begin{array}{l}\text { March 2012 to } \\
\text { August 2012 }\end{array}$ & $\begin{array}{l}\text { September 2012 to } \\
\text { February 2013 }\end{array}$ & $\begin{array}{l}\text { March 2013 to } \\
\text { August 2013 }\end{array}$ & $\begin{array}{l}\text { September 2013 to } \\
\text { February 2014 }\end{array}$ & $\begin{array}{l}\text { March 2014 to } \\
\text { August 2014 }\end{array}$ \\
\hline Lambeth & 5109 & 5056 & 4963 & First attendances & & \\
Lewisham & 4077 & 4189 & 4030 & 4923 & 4740 & 4711 \\
Southwark & 4397 & 4387 & 4330 & 3197 & 2747 & 2691 \\
\hline Lambeth & 11448 & 11611 & 12244 & 4100 & 4143 & 4102 \\
\hline Lewisham & 9599 & 10909 & 11318 & 11699 & 12365 & 12292 \\
Southwark & 9429 & 10112 & 10450 & 9719 & 10209 & 9875 \\
\hline
\end{tabular}

Follow-up attendances were differentially reduced by $16.7 \%(95 \% \mathrm{CI}-0.313 \%$ to $-0.021 \%)$ at Hospital $\mathrm{A}$ and by $14.6 \%$ (95\% CI $-0.232 \%$ to $-0.059 \%$ ) at other providers.

The picture is different for Lewisham-at the largest provider (Hospital B), GP referrals to hospital ophthalmology were differentially reduced by $75.2 \%$ (95\% CI $-0.918 \%$ to $-0.587 \%$ ) compared with Southwark for first attendances and by $40.3 \%$ (95\% CI $-0.489 \%$ to $-0.316 \%$ ) for follow-up visits. We also find that referrals from hospital consultants differentially increased by $68.6 \%$ (95\% CI $0.365 \%$ to $1.007 \%$ ) for first attendances, and $49.4 \%$ (95\% CI $0.348 \%$ to $0.639 \%$ ) for follow ups (compared with Southwark).

Table 4 shows the volumes of patients treated at hospitals and ITS in 2011-2012 and 2013-2014 and associated costs in each of the three areas. The unit costs are fixed across areas and time periods and so changes in total costs are attributable only to changes in the volume of activity. The overall changes are summarised in table 5 . Overall, the total costs for hospital and ITS activity were 2.5\% higher for Lambeth in 2013-2014 compared with 2011-2012. They were $13.8 \%$ lower in Lewisham. In the comparison area (Southwark), total costs were $3.1 \%$ higher in 2013-2014 compared with 2011-2012.

Tables 6 and 7 present data on the reasons for patient referral into MECS, the proportion of patients managed by community optometrists, the proportion discharged with no pathology and the percentages referred to the Hospital Eye Service (HES) and GP. The majority of patients presented with minor anterior eye disease

Table 3 Difference-in-differences estimates by referral type for first and follow-up visits

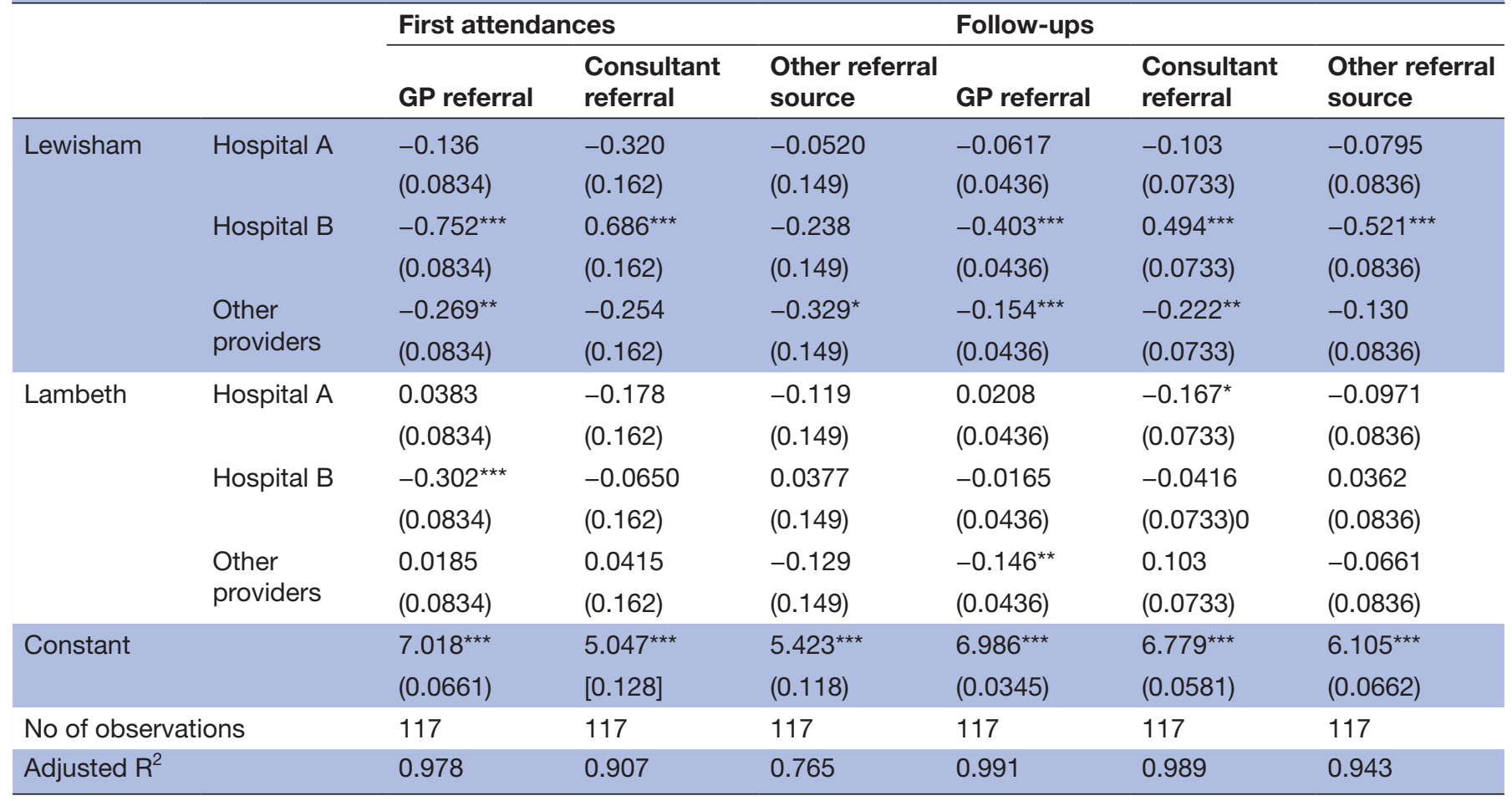

SE in brackets.

${ }^{\star} \mathrm{p}<0.05,{ }^{* \star} \mathrm{p}<0.01,{ }^{\star \star *} \mathrm{p}<0.001$; quarter dummies and provider- commissioner combination fixed effects included. 


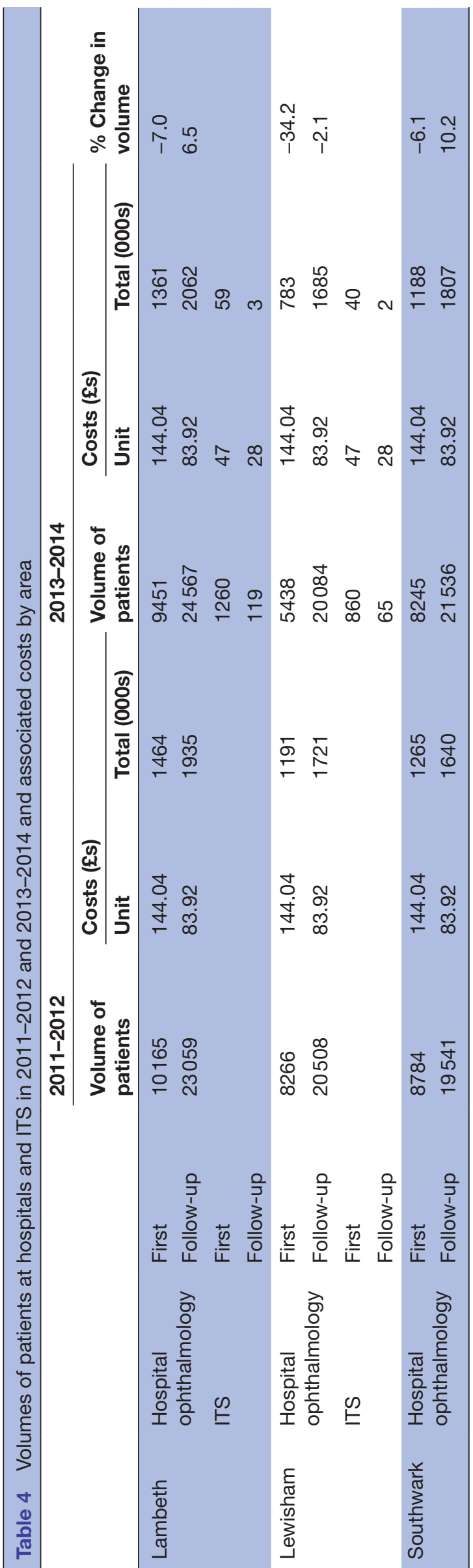

and over $80 \%$ of these patients were managed by their community optometrist.

\section{DISCUSSION}

There is very little previous research that investigates whether shifting care from hospitals to community providers is successful in reducing overall healthcare system costs. In particular, little is known about how new ITS affect demand and supply in the wider healthcare system. This study used an application from ophthalmology to consider how introducing enhanced eye services in the community changed the number of first and follow-up attendances to hospital. We used a difference-in-differences approach, comparing two areas (Lambeth and Lewisham) that introduced an ITS to a neighbouring comparison area (Southwark) that did not.

The results of this study describe a complicated picture-the changes we observe are not wholly consistent across the two intervention areas and are especially concentrated at the largest provider for Lewisham patients (the commissioning area in which we find the largest reductions in activity). We find that first and follow-up attendances for GP referrals were substantially reduced in the post-ITS period, and that first and follow-up attendances for consultant referrals were increased. Figure 1 shows that GP referrals comprise the majority share of overall activity-and so the net effect of these changes is still a significant reduction in hospital activity.

Annual costs in Lewisham decreased by $13.8 \%$ between 2011-2012 and 2013-2014-the consequences of larger reductions to more costly activity (hospital treatment) being considerably greater than the increase in less costly activity (ITS treatment). Annual costs increased by $2.5 \%$ in Lambeth and by $3.1 \%$ in the comparison area (Southwark) during the same period.

The increase in consultant referrals observed for Lewisham patients treated at Hospital B might theoretically be explained by changes to coding practices at Hospital B (or a similar change such as diagnostic practice), but we do not observe consistent changes for Lambeth patients treated at Hospital B. This increase is smaller in percentage terms than the reduction in GP referrals and there is a much smaller number of consultant to consultant referrals than referrals from GPs.

Differences in how the enhanced services were structured and used between the two intervention areas may offer possible explanations for the variation in the estimated effects. The Lewisham scheme was concentrated in just five optometry practices, whereas eight practices participated in Lambeth and rates of use varied substantially. There was a difference between the two areas in the referral sources into MECS, with approximately $56 \%$ of all patients seen in Lambeth referred by a GP compared with $75 \%$ in Lewisham. Finally, there was much higher level of GP engagement in the scheme in Lewisham: $90 \%$ of GP practices registered compared with $78 \%$ in Lambeth. 
Table 5 Total costs by area in 2011-2012 and 2013-2014

\begin{tabular}{llll}
\hline & \multicolumn{2}{l}{ Total costs (£000s) } \\
\cline { 2 - 4 } & $\mathbf{2 0 1 1 - 1 2}$ & $\mathbf{2 0 1 3 - 1 4}$ & \% Change \\
\hline Lambeth & 3399 & 3486 & 2.5 \\
Lewisham & 2912 & 2511 & -13.8 \\
Southwark & 2905 & 2995 & 3.1 \\
\hline
\end{tabular}

It is possible that the changes in patient volumes in the areas that introduced an ITS were caused by factors other than the ITS. The lack of reductions in patient volumes in Southwark might have been caused by changes in other factors in Southwark. These areas, however, had very similar characteristics and are geographically very close. Patients in these areas make use of the same hospitals and would therefore be expected to experience similar changes in access over this short time period. There were no other policy initiatives or care pathway changes introduced during this period. Our findings are not necessarily generalisable across the UK. Future

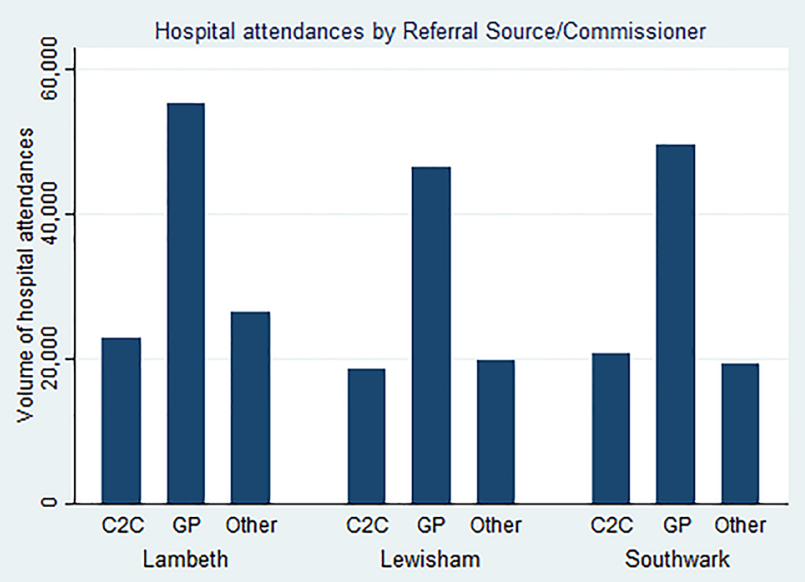

Figure 1 Hospital attendances by referral source/ commissioner. C2C, consultant to consultant; GP, general practitioner.

Table 6 Management of patients by provisional diagnosis

\begin{tabular}{llll} 
Optometrists' provisional diagnosis & $\begin{array}{l}\text { Patients retained in the } \\
\text { community (\%) }\end{array}$ & $\begin{array}{l}\text { Patients referred to } \\
\text { hospital (\%) }\end{array}$ & $\begin{array}{l}\text { Patients referred to } \\
\text { the GP (\%) }\end{array}$ \\
\hline Eyelid, lacrimal system, orbit $(n=412)$ & 81.3 & 14.6 & 4.1 \\
\hline Diseases of the conjunctiva $(n=408)$ & 87.5 & 4.7 & 7.8 \\
\hline Disorders of the cornea and sclera $(n=536)$ & 82.6 & 13.8 & 3.5 \\
\hline Disorders of the iris and ciliary body $(n=29)$ & 3.4 & 93.1 & 3.4 \\
Disorders of the lens $(n=45)$ & 60 & 40 & 0 \\
Disorders of choroid and retina $(n=96)$ & 6.3 & 90.6 & 3.1 \\
Glaucoma $(n=38)$ & 10.5 & 86.8 & 2.6 \\
Disorders of vitreous body and globe $(n=142)$ & 82.4 & 17.6 & 0 \\
Disorders of optic nerve and visual pathway $(n=6)$ & 0 & 100 & 0 \\
Disorders of ocular muscles, binocular movement, & 87.3 & 11.1 & 1.6 \\
accommodation and refraction $(n=63)$ & & & 15.5 \\
Visual disturbances and blindness $(n=58)$ & 60.3 & 24.1 & \\
\hline
\end{tabular}

Table 7 Management of patients by reason for presentation

\begin{tabular}{lllll}
\hline $\begin{array}{l}\text { Reason for MECS visit } \\
\text { N (\%) }\end{array}$ & $\begin{array}{l}\text { \% of patients managed by } \\
\text { the community optometrist }\end{array}$ & $\begin{array}{l}\text { Patients with no ocular } \\
\text { pathology identified (\%) }\end{array}$ & $\begin{array}{l}\text { Patients referred the HES (\%) } \\
\text { to }\end{array}$ & $\begin{array}{l}\text { Patients referred } \\
\text { to GP (\%) }\end{array}$ \\
\hline Red eye $(n=777)$ & 79.3 & 1.3 & 14.7 & 4.5 \\
\hline Painful white eye $(n=216)$ & 64.4 & 15.7 & 14.0 & 5.9 \\
\hline Flashes/floaters $(n=236)$ & 61.6 & 10.6 & 25.9 & 1.4 \\
\hline Loss of vision $(n=194)$ & 22.7 & 21.1 & 51.0 & 4.6 \\
\hline Headaches $(n=112)$ & 11.6 & 51.8 & 9.8 & 26.8 \\
\hline Trauma $(n=36)$ & 63.9 & 27.8 & 8.3 & 0.0 \\
\hline Diplopia $(n=8)$ & 12.5 & 0.0 & 75.0 & 12.5 \\
\hline Other $(n=538)$ & 22.7 & 21.1 & 51.0 & 4.6 \\
\hline
\end{tabular}

Swollen lid/lid lump 21.7\%; Watery eyes 19.8\%; Itchy eyes 10.0\%; Foreign body sensation, sore/dry/gritty eyes 14.8\%; A reason for MECS visit was not provided for six patients.

GP, general practitioner; HES, Hospital Eye Service; MECS, Minor Eye Conditions Scheme. 
studies should evaluate the cost-effectiveness of these schemes and the impact on patient outcomes.

A high proportion of MECS patients are retained in the community, of whom a considerable proportion have no eye disease (tables 6 and 7). Although we have no data on patients who might be subsequently referred by their GP to the HES or who self-refer to Accident and Emergency (A \& E) after their MECS evaluation, it is likely that the majority of these patients will not reach the HES as a result of this episode and so will avoid the higher hospital tariff. Recently published qualitative research on MECS revealed a very high degree of satisfaction among patients with the scheme which suggests only a minority of patients would be likely to represent at HES clinics. ${ }^{12}$

Introducing community-based enhanced services may potentially reduce the pressure on secondary care providers, possibly as a result of reduced referrals from primary care. Although we do not know the effect on final patient outcomes, the proportion of cases seen at the ITS that were judged to have been appropriately managed was very high and patients reported high levels of satisfaction. ${ }^{13}$ The potential success of these ITS schemes requires broad support from participating optometrists, ophthalmologists and GPs. ${ }^{14}$

\section{Author affiliations}

${ }^{1}$ Manchester Centre for Health Economics, University of Manchester, Manchester, UK

${ }^{2}$ Division of Optometry and Visual Science, Applied Vision Research Centre, University of London, London, UK

${ }^{3}$ NIHR Biomedical Research Centre, Moorfields Eye Hospital NHS Foundation Trust, London, UK

${ }^{4}$ Institute of Ophthalmology, University College London, London, UK

${ }^{5}$ Manchester Academic Health Sciences Centre, Central Manchester University Hospitals NHS Foundation Trust and University of Manchester, Manchester, UK ${ }^{6}$ Department of Clinical Epidemiology and Biostatistics and Centre for Health Economics and Policy Analysis, McMaster University, Ontario, Canada

Acknowledgements We are grateful to Alicia Reeves (Lambeth CCG) and Nick Harris (Southwark CCG) for providing the hospital data.

Contributors The analysis and interpretation of the data were undertaken by MS, $\mathrm{TM}, \mathrm{CJ}$ and SB. The paper was drafted by CJ and TM. All authors contributed to the design of the study and approved the final version of the paper.

Funding Thisresearch was funded by the College of Optometrists.

Disclaimer The views expressed are the authors' sole responsibility.

Competing interests None declared.
Ethics approval The study was approved by the Research and Ethics Committee of the School of Health Sciences, City University London and followed the principles of the Declaration of Helsinki.

Provenance and peer review Not commissioned; externally peer reviewed.

Data sharing statement The data used in this study are not publicly available with the exception of the cost data.

Open Access This is an Open Access article distributed in accordance with the Creative Commons Attribution Non Commercial (CC BY-NC 4.0) license, which permits others to distribute, remix, adapt, build upon this work non-commercially, and license their derivative works on different terms, provided the original work is properly cited and the use is non-commercial. See: http://creativecommons.org/ licenses/by-nc/4.0/

(C) Article author(s) (or their employer(s) unless otherwise stated in the text of the article) 2017. All rights reserved. No commercial use is permitted unless otherwise expressly granted.

\section{REFERENCES}

1. Atun R. What are the advantages and disadvantages of restructuring a health care system to be more focused on primary care services? Copenhagen: World Health Organization Publisher, 2004.

2. Propper $\mathrm{C}$. The disutility of time spent on the United Kingdom's National Health Service waiting lists. J Hum Resour 1995;30:677-700.

3. Propper C, Sutton M, Whitnall C, et al. Incentives and targets in hospital care: evidence from a natural experiment. J Public Econ 2010;94:318-35.

4. Coast J, Noble S, Noble A, et al. Economic evaluation of a general practitioner with special interests led dermatology service in primary care. BMJ 2005;331:1444-9.

5. Renders CM, Valk GD, Griffin SJ, et al. Interventions to improve the management of diabetes in primary care, outpatient, and community settings: a systematic review. Diabetes Care 2001;24:1821-33.

6. Sibbald B, McDonald R, Roland M. Shifting care from hospitals to the community: a review of the evidence on quality and efficiency. $J$ Health Serv Res Policy 2007;12:110-7.

7. Sibbald B, Pickard S, McLeod H, et al. Moving specialist care into the community: an initial evaluation. J Health Serv Res Policy 2008;13:233-9.

8. The General Optical Council (Rules relating to Injury or Disease of the Eye) Order of Council 1999. SI No.3267. http://www.legislation.gov. uk/uksi/1999/3267/contents/made. (accessed 01 May 2014).

9. Gillam SJ, Ball M, Prasad M, et al. Investigation of benefits and costs of an ophthalmic outreach clinic in general practice. $\mathrm{Br} J$ Gen Pract 1995;45:649.

10. Baker H, Ratnarajan G, Harper RA, et al. Effectiveness of UK optometric enhanced eye care services: a realist review of the literature. Ophthalmic Physiol Opt 2016;36:545-57.

11. Imbens GW, Wooldridge JM. Recent developments in the econometrics of program evaluation. J Econ Lit 2009;47:5-86.

12. Baker H, Harper RA, Edgar DF, et al. Multi-stakeholder perspectives of locally commissioned enhanced optometric services. BMJ Open 2016;6:e011934.

13. Konstantakopoulou E, Edgar DF, Harper RA, et al. Evaluation of a minor eye conditions scheme delivered by community optometrists. BMJ Open 2016;6:e011832.

14. Konstantakopoulou E, Harper RA, Edgar DF, et al. A qualitative study of stakeholder views regarding participation in locally commissioned enhanced optometric services. BMJ Open 2014;4:e004781. 